\title{
Endoscopic ultrasound-guided hepaticogastrostomy combined with antegrade stenting using a double bare covered metal stent
}

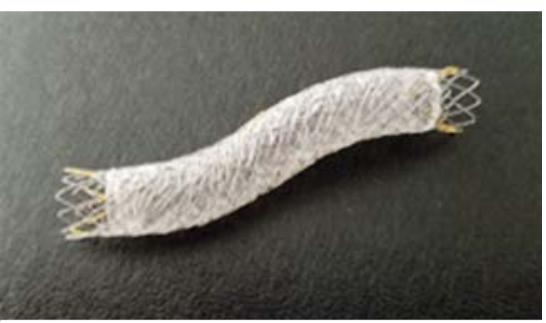

- Fig. 1 The double bare, partially covered, self-expandable metal stent (EGIS Biliary Stent; S\&G Biotech Inc., Yongin-si, Korea).

Endoscopic ultrasound-guided hepaticogastrostomy (EUS-HGS) has been indicated for failed endoscopic retrograde cholangiopancreatography (ERCP) [1,2]. Recently, to obtain a longer duration of stent patency or avoid adverse events, EUS-HGS combined with antegrade stenting (EUS-HGAS) has been reported $[3,4]$.In this procedure, an uncovered, self-expandable, metal stent (UCSEMS) is usually used to avoid stent dislocation. However, compared with a fully covered, self-expandable, metal stent (FCSEMS), longer stent patency may not be achieved [5]. A novel, double bare, partially covered, self-expandable, metal stent (D-FCSEMS, EGIS Biliary Stent; S\&G Biotech Inc., Yongin-si, Korea) ( $\bullet$ Fig. 1) has become available in Japan. This stent has low axial force compared with conventional FCSEMS, and high radial force compared with conventional UCSEMS. Therefore, this stent may be suitable for EUS-HGAS. Herein, we describe technical tips for EUS-HGAS using the D-FCSEMS $(\triangleright$ Video 1$)$.

An 82-year-old man was admitted to our hospital with obstructive jaundice caused by advanced pancreatic cancer.

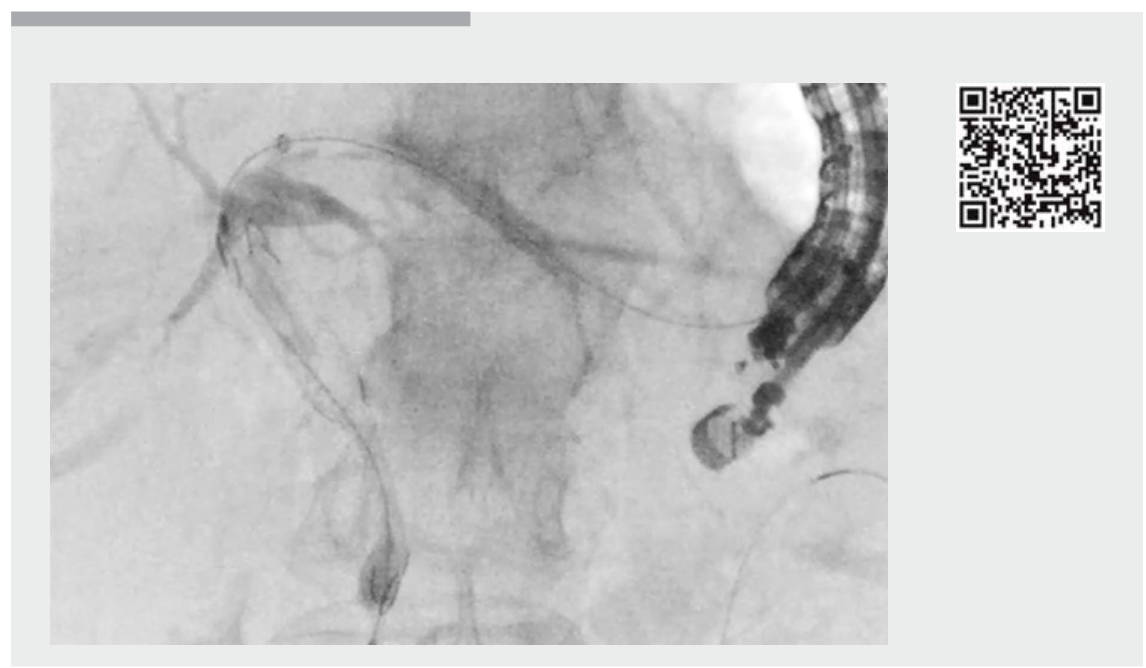

Video 1 The intrahepatic bile duct was punctured using a 19-gauge fine-needle aspiration needle, and contrast medium was injected. Then, the guidewire was inserted into the biliary tract, followed by a balloon catheter; contrast medium was injected again. After the guidewire was advanced into the intestine across the obstruction site, a double bare, partially covered, self-expandable, metal stent was deployed. Finally, endoscopic ultrasoundguided hepaticogastrostomy was successfully performed.

Although ERCP was attempted, the duodenoscope could not be advanced into the duodenum owing to duodenal obstruction from pancreatic cancer invasion. Therefore, EUS-guided biliary access was attempted.

First, the intrahepatic bile duct was punctured using a 19-gauge needle under EUS guidance, and contrast medium was injected ( $\triangleright$ Fig. 2 a). A guidewire was inserted into the biliary tract, followed by a balloon catheter. Next, contrast medium was injected to evaluate the biliary obstruction site. The cholangiograph showed the middle common bile duct to be obstructed ( $\vee$ Fig. $\mathbf{2 b}$ ). The intrahepatic bile duct and stomach wall were then dilated using the balloon catheter, and deployment of the D-FCSEMS stent
$(10 \mathrm{~mm} \times 6 \mathrm{~cm})$ from the lower common bile duct to the upper common bile duct was successfully performed ( $\mathbf{F i g . 2 c}$ ). Finally, FCSEMS deployment was performed from the intrahepatic bile duct to the stomach without any adverse events ( $\vee$ Fig. $2 \mathrm{~d}$ ).

Although additional cases are needed to determine the clinical impact of DFCSEMS placement, the D-FCSEMS may be a suitable stent to use for EUS-HGAS.

Endoscopy_UCTN_Code_TTT_1AR_2AI

Competing interests

None 

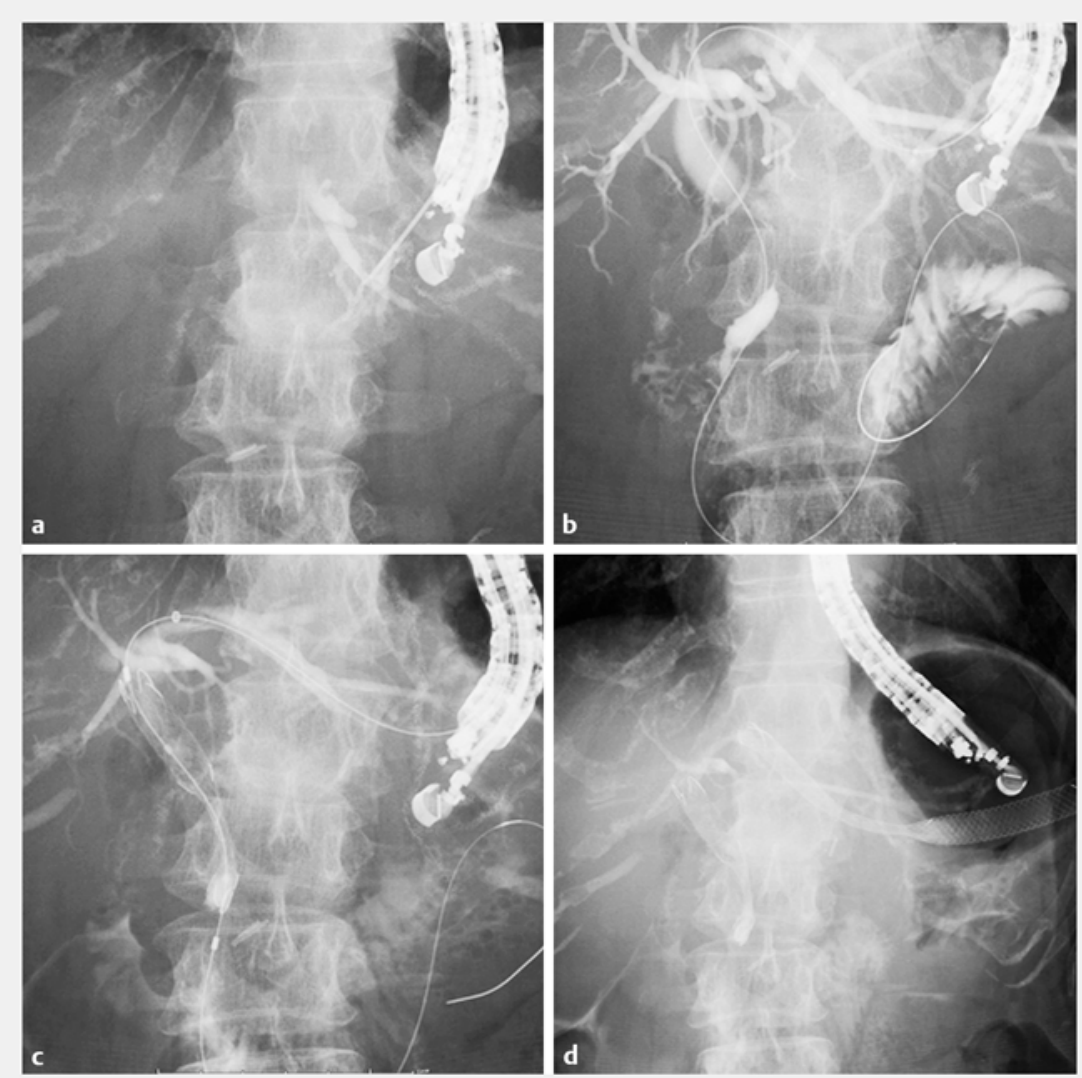

- Fig. 2 Cholangiography. a The intrahepatic bile duct was punctured using a 19-gauge needle, and contrast medium was injected. $\mathbf{b}$ Obstruction of the middle common bile duct was seen. c Antegrade stent deployment from the lower to the upper common bile duct was performed using the double bare, partially covered, self-expandable, metal stent. d Endoscopic ultrasound-guided hepaticogastrostomy was successfully performed.
The authors

Takeshi Ogura, Nobu Nishioka, Akira Miyano, Rieko Kamiyama, Kazuhide Higuchi

2nd Department of Internal Medicine, Osaka Medical College, Osaka, Japan

\section{Corresponding author}

\section{Takeshi Ogura, MD}

2nd Department of Internal Medicine, Osaka

Medical College, 2-7 Daigakuchou,

Takatsukishi, Osaka 569-8686, Japan

Fax: +81-72-6846532

oguratakeshi0411@yahoo.co.jp
[1] Boulay BR, Lo SK. Endoscopic ultrasoundguided biliary drainage. Gastrointest Endosc Clin N Am 2018; 28: 171 - 185

[2] Baars JE, Kaffes AJ, Saxena P. EUS-guided biliary drainage: a comprehensive review of the literature. Endosc Ultrasound 2018; 7: 4-9

[3] Ogura T, Masuda D, Imoto A et al. EUSguided hepaticogastrostomy combined with fine-gauge antegrade stenting: a pilot study. Endoscopy 2014; 46: 416-421

[4] Ogura T, Kitano M, Takenaka M et al. Multicenter prospective study of endoscopic ultrasound-guided hepaticogastrostomy combined with antegrade stenting (with video). Dig Endosc 2018; 30: 252-259

[5] Kitano M, Yamashita Y, Tanaka K et al. Covered self-expandable metal stents with an anti-migration system improve patency duration without increased complications compared with uncovered stents for distal biliary obstruction caused by pancreatic carcinoma: a randomized trial. Am J Gastroenterol 2013; 108: 1713-1722

\section{Bibliography}

DOI https://doi.org/10.1055/a-0767-6171

Published online: 23.11.2018

Endoscopy 2019; 51: E24-E25

(c) Georg Thieme Verlag KG

Stuttgart · New York

ISSN 0013-726X

\section{ENDOSCOPY E-VIDEOS}

https://eref.thieme.de/e-videos

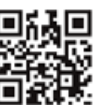

Endoscopy E-Videos is a free access online section, reporting on interesting cases and new techniques in gastroenterological endoscopy. All papers include a high quality video and all contributions are freely accessible online.

This section has its own submission website at

https://mc.manuscriptcentral.com/e-videos 